\title{
The Role OF GeOgRaPHICAL Distance ON THE RELATIONSHIP BETWEen CULTURAL INTELLIGENCE AND KNOWLEDGE TrANSFER
}

\author{
Business Process Management Journal
}

Link to Full Paper (DOI): http://dx.doi.org/10.1108/BPMJ-05-2017-0129

\author{
Davor Vlajčić \\ University of Zagreb Faculty of Economics and Business, \\ J.F.Kennedy Square 6 \\ 10000 Zagreb, Croatiaf \\ Giacomo Marzi \\ Lincoln International Business School, \\ University of Lincoln, \\ Lincoln, $U K$ \\ gmarzi@lincoln.ac.uk \\ Andrea Caputo * \\ Lincoln International Business School, \\ University of Lincoln, \\ Lincoln, $U K$ \\ acaputo@lincoln.ac.uk \\ Marina Dabić \\ University of Zagreb Faculty of Economics and Business, \\ J.F.Kennedy Square 6 \\ 10000 Zagreb, Croatia \\ mdabic@efzg.hr \\ $\&$ \\ Nottingham Trent University, \\ Burotn street NG1 4 BU Nottingham, UK \\ marina.dabic@ntu.ac.uk
}


Davor Vlajčić is a Post-doctoral student in Business Economy at the University of Zagreb (HR), with a research focus in international business - internationalization modes, knowledge management - knowledge transfer. He received his $\mathrm{PhD}$ in Business from the University of Zagreb (HR). In her carrier, he achieved success in working on numerous national and European projects. Davor is also a Visiting Scholar in the Scuola Superiore Sant'Anna (IT).

Giacomo Marzi is a Ph.D. student in Management and Business Administration at the University of Pisa (IT), and his research is mainly focused on innovation management, entrepreneurship and bibliometric. He has authored and co-authored a number of papers that appeared in journals such as Business Process Management Journal and the International Journal of Innovation and Technology Management. His work has also been presented at conferences such as the Academy of Management and the European Academy of Management. Giacomo is also a Visiting Scholar in the University of Zagreb (HR).

Andrea Caputo is Reader in Entrepreneurship at the Lincoln International Business School (UK). He received his $\mathrm{PhD}$ in Management from the University of Rome Tor Vergata (IT). He has also been a Visiting scholar at the University of Queensland Business School (AU), at The George Washington School of Business (USA), and at the University of Pisa (IT). His main research interests are related to negotiation, decision-making, entrepreneurship and strategic management. He published in several international journals, including BPMJ, JBR, and EBR. His work has also been presented at many international conferences, such as the AOM, EURAM, BAM and IACM.

Marina Dabic is a Full Professor of International Business and Entrepreneurship. She has edited several special issues on innovation, internationalisation, HRM and transfer technology. She published more than 50 papers appeared in wide variety of international journals including JIBS, JWB, JBE, IMR, EMJ, TBR, IJPDLM EBR and MIR among others. In her carrier, she achieved success in working on numerous projects, has been reviewer for Horizon 2020 projects as well as the grant holder of projects financed by European commission. 


\section{Abstract}

Purpose: This paper's purpose is to investigate the ways in which the geographical distance between headquarters and subsidiaries moderates the relationship between cultural intelligence and the knowledge transfer process.

Design/methodology/approach: A sample of 103 senior expatriate managers working in Croatia from several European and non-European countries was used to test the hypotheses. Data were collected using questionnaires, while the methodology employed to test the relationship between the variables was Partial least square. Furthermore, interaction-moderation effect was utilised to test the impact of geographical distance and, for testing control variables, Partial least square multigroup analysis was used.

Findings: Cultural Intelligence plays a significant role in the knowledge transfer process performance. However, geographical distance has the power to moderate this relationship based on the direction of knowledge transfer. In conventional knowledge transfer, geographical distance has no significant impact. On the contrary, data have shown that, in reverse knowledge transfer, geographical distance has a moderately relevant effect. We supposed that these findings could be connected to the specific location of the knowledge produced by subsidiaries.

Practical implications: Multinational companies should take into consideration that the further away a subsidiary is from the headquarters, and the varying difference between cultures, cannot be completely mitigated by the ability of the manager to deal with cultural differences, namely cultural intelligence. Thus, multinational companies need to allocate resources to facilitate the knowledge transfer between subsidiaries.

Originality/value: The present study stresses the importance of cultural intelligence in the knowledge transfer process, opening up a new stream of research inside these two areas of research.

Keywords: knowledge transfer; cultural intelligence; geographical distance; performance; MNC; senior manager expatriates; Croatia. 


\section{Introduction}

In a highly complex, interconnected, and demanding global environment, understanding organisations' capabilities to manage scarce resources is of pivotal importance for management scholars and practitioners. This need is particularly important when referring to Multinational Companies (MNCs) because the geographical and cultural disparity of its units heightens the complexity of its governance (Ghemawat and Hout, 2008). Although vast networks of units around the world allow MNCs to gain significant advantages, their geographical distance creates several challenges for their business models in terms of costs associated with physical and cultural disparity (Ambos and Ambos, 2009; Håkanson and Ambos, 2010; Caputo et al, 2016). Another element of complexity arises from the fact that the world becomes more globalized every day, as such diverse cultures are incessantly meeting, thus creating a strong need for cultural adaptation (Peterson, 2004; Rose at al., 2010). In this vein, Earley and Ang (2003) developed the concept of Cultural Intelligence which is the capability to acclimate, relate to, and work effectively in an unfamiliar and culturally diverse environment or situation (Gonzalez-Loureiro et al, 2015). Since its theorization, scholars have contended that Cultural Intelligence is essential to successfully communicate across cultures, easing the organizational complexities arising from globalization (Earley and Ang, 2003; Marzi et al., 2017). Therefore, managers that have the capacity to handle the culturally diverse business settings in which they operate are favoured very highly and are in strong demand (Groves and Feyerherm, 2011). This is because their abilities enable them to shape performance outcomes (Ang et al., 2007).

Moreover, among the main issues for sustaining competitive advantage in MNCs are the processes of knowledge transfer (Tallman and Phene, 2007; Mudambi and Swift, 2014). Knowledge transfer could generally be observed as a process of communication, wherein the organization's members learn from each other without integration to environment (Kalling, 2003). This paper deals with the vertical flows in the context of the relationship between the headquarters and a subsidiary. Knowledge transfer between headquarters and a subsidiary can be categorised according to its direction: from the headquarters to the subsidiary (conventional knowledge transfer) and from the subsidiary to the headquarters (reverse knowledge transfer).

Thus, as several previous studies have suggested, there is a connection between Cultural Intelligence and knowledge transfer (Buckley et al., 2006; Lee and Sukoko, 2010; Boh et al., 2013). As a result of the expatriate manger's position as a "link" between MNCs and subsidiaries, cultural awareness could be a facilitator in their process of knowledge transfer (López-Duarte, et al, 2016). In knowledge transfer process among units of MNCs, geographical distance (the physical distance express in kilometres (Hansen and Løvås, 2004) plays an important role. When the subsidiary and the headquarters are located far away from each other, for example one in Europe and the other in the US, we can expect cultural differences to arise and hinder the effect of cultural intelligence of expatriate managers on knowledge transfer processes (Van Vianen et al, 2004; Colakoglu \& Caligiuri, 2008). Therefore, geographical distance is presented as a barrier (Petruzzelli, 2001; Harzing and Noorderhaven, 2006; Holmstrom et al., 2006), while the expatriate managers and their cultural awareness are presented as facilitators of the knowledge transfer process (Minbaeva et al., 2003). The motive of this research is the lack of literature on the combined effect of manager traits and geographical distance in the process of knowledge transfer. To solve this literature gap, this paper investigates senior expatriate managers and their role in solving the issues arising from a more 
globalized, culturally diverse, and distant world of business affecting the knowledge transfer processes in MNCs (Minbaeva et al., 2003; Barry Hocking et al., 2004; Minbaeva and Michailova, 2004). Given the fact that expatriates live in a different country, they serve as an ideal unit of investigation when attempting to understand the ways in which Cultural Intelligence and geographical distance relate to the KT processes. This research aims to interrogate the role played by cultural intelligence in the knowledge transfer process, and question the impact of geographical distance on this relationship. Thus, the present research was conducted on 103 senior expatriate managers who are active in subsidiaries of foreign MNCs, and the data are collected using the questionnaire method. Analysis of collected data has been made using a Partial least square (PLS) method and processed with SmartPLS 3.0 software.

The paper is structured as follows. In the next section, we provide an extensive literature review about Cultural Intelligence and several key issues connected with knowledge transfer in MNCs. Then, the third section is dedicated to the development of hypotheses, while Section Four presents the sample and methodology applied. Section Five stresses the results that arose from the data and discusses the role of geographical distance and Cultural Intelligence in Conventional KT and Reverse KT. The last section presents our conclusions, limitations, and insights for future research.

\section{Literature Review}

\subsection{Knowledge Transfer as a Business Process}

According to Forsten-Astikainen (2010), knowledge transfer could generally be observed as a process of communication, wherein the organization's members learn from each other without integration to environment (Kalling, 2003). The single most important recognition about the knowledge transfer complexity arises from its process, rather than its actual characteristics (Szulanski, 2000), indicating dynamic, instead of static, traits of knowledge transfer. Observing it as a process allows for easier detection of emerging difficulties and, as a result, allows for intervention and the possibility of redesigning organizational mechanisms which support knowledge transfer (Szulanski, 2000). The beginning of the models of the knowledge transfer process can be traced back to the mid- $20^{\text {th }}$ century, when knowledge transfer was described using the classical communication model originally presented by Shannon and Weaver (1949). After Shannon and Weaver developed the initial model of knowledge transfer process, other models were proposed (Liyanage, Elhag, and Ballal, 2009; Frank and Ribeiro, 2012) hoping to fulfil the research hunger and explain the knowledge transfer process. However, the importance of knowledge transfer processes also finds its recognition in international business literature, claiming that one of the primary factors for upsurge in MNCs' competitive advantage, is its ability to efficiently process knowledge across borders (Tallman and Phene, 2007; Mudambi and Swift, 2014). However, it is exactly this cross-border activity that creates a challenge, since the knowledge tends to often be highly tacit, or part of the environment and culture in which it is developed (Cantwell and Mudambi, 2005). As a result, both internal and external factors can make the process of knowledge transfer difficult to achieve, and its global application can be called into question (Bezerra et al., 2013). As such, the act of transferring knowledge-based assets across borders should not be taken lightly. Throughout years of academic interest in knowledge transfer processes, crude categorization of research streams on intra-MNC knowledge transfer processes have been developed. Along this line, Grosse (1996) maintains that all knowledge transfer processes in MNCs fall into either one of two categories - vertical or horizontal. Vertical knowledge transfer process 
refers to the transfer of knowledge from the parent firm to its subsidiary, and vice versa (Yang et al, 2008); while horizontal knowledge transfer process denotes the transfer of knowledge from a subsidiary to its peer subsidiaries (Najafi-Tavani et al., 2014).

For this paper, emphasis will be placed on vertical flows in the context of the relationship between the headquarters and a subsidiary, and inside vertical flows of knowledge, where literature establishes a difference between Conventional and Reverse KT (from now on referred to as Conventional KT and Reverse KT). Conventional KT presents a process of transferring knowledge from headquarters to subsidiary, and Reverse KT presents a process of transferring knowledge from subsidiary to headquarters. The two processes mentioned above are conceptually very similar; however, their transfer logic differs significantly. The former refers to a training process in which the subsidiary is often under compulsion to adapt knowledge from the parent firm through transplantation or supplementation. The latter is a more complex process, based on persuading, where subsidiaries are motivated to share their knowledge with the parent company in order to improve or strengthen their strategic position (Yang et al., 2008).

The intra-MNC knowledge transfer process started to receive attention in the late 1960s within 'home-centric view', i.e. the Hymer-Kindleberger approach (Hymer, 1976). Knowledge transfer processes were used to search for competitive advantages for subsidiaries based on knowledge received from headquarters (Mudambi et al., 2014; Ambos, et al., 2006). Parent companies play an integral role as a source of knowledge for their subsidiaries because they possess valuable intangible assets, influence, and capabilities (Piscitello, 2004) that can give subsidiaries considerable advantages, allowing them to prosper and advance in local markets that are highly competitive (Kuemmerle, 1999). For many decades, MNCs have remained the principal providers of knowledge and technology that flow to less developed countries, achieving this by establishing subsidiaries which have developed or acquired capabilities of their own (Saliola and Zanfei, 2009).

Nevertheless, the trend is shifting in the direction of international markets, and MNC's choices to gain international exposure are partly motivated by the desire to absorb foreign knowledge which, in turn, can lead to improvements or advancements in technology (e.g., Caputo et al., 2016; Andersson et al., 2016). Furthermore, a wealth of knowledge produced by subsidiary companies has the potential to be a valuable resource for the headquarters along with other subsidiaries. In this vein, Millar and Choi (2009) define Reverse KT as "the process of transfer of tacit and explicit knowledge from a MNC's subsidiaries to its headquarters" (Millar and Choi, 2009, p. 390).

In addition, current studies confirm and bolster the significance of Reverse KT by placing emphasis on the growing dispersion of knowledge creation, which suggests that the notion of headquarters supposed knowledge supremacy is true for fewer and fewer companies today (Ambos et al., 2006), whereas it is highly probable that Reverse KTs could contribute extensively to the development of an MNC's competitive advantage in the markets.

\subsection{MNC, Geographical Distance and Knowledge Transfer}

As MNC's networks have become more and more global, the role of geographical distance in the knowledge transfer process has received inadequate attention in business literature. Few studies have stressed the role of geographical distance between headquarters and subsidiaries on management practices, highlighting interesting results. Thus, geographical distance between MNCs and subsidiaries refers to the physical distance expressed in kilometres or miles between the two firms 
(Hansen, and Løvås, 2004). A seminal study of Ghoshal and Bartlett (1988) found that the ability of a subsidiary to diffuse knowledge to the rest of the MNC is positively associated with what they call "normative integration". The extent to which a subsidiary is normatively integrated with the parent company and shares its overall strategy, goals, and values for Ghoshal and Bartlett (1988: 371) is associated with practices like "extensive travel and transfer of managers between the headquarters and the subsidiary" and "joint-work in teams, task forces, and committees". More recently, Gupta and Govindarajan (2000) found that corporate socialization mechanisms influence knowledge inflows and outflows, both to and from headquarters and other subsidiaries. Apparently, expensive communication media allowing for face-to face communication, informal interaction, and teamwork help to overcome the "transmission losses" that occur when complex knowledge is transferred (Mudambi 2002). However, the geographical isolation of subsidiaries in the Oceanic continent renders this kind of interaction more difficult, impeding the transfer of knowledge (Gupta and Govindarajan, 2000).

Directly connected with the above-mentioned studies, Harzing and Noorderhaven (2006), using a survey covering 169 subsidiaries, stressed the impact of geographical distance in Australian and New Zealander subsidiaries which represent significant examples of geographical isolation. Surprisingly, they found that, with regard to the knowledge transfer processes in Australian and New Zealander subsidiaries, the level of inflow and outflow knowledge does not differ significantly from other subsidiaries and hence geographical isolation does not seem to prohibit knowledge flows. However, the authors pointed out that a possible explanation could be related to the increasing availability of new communication technologies, in combination with English language proximity. More recently, on the strategic decision side, several studies (Zaheer et al., 2012; Asmussen and Goerzen, 2013; Baaij and Slangen; 2013) have disputed the role of geographic distance between the corporate headquarters of a MNC and a subsidiary, demonstrating its effect on strategic decisions related to plants, distribution centres, sales outlets, research and development facilities, and regional headquarters. These studies generally demonstrated that larger geographical distances increased the difficulty and the cost in the communication between headquarters and subsidiaries, especially in exchanging knowledge. In fact, transfer of codified knowledge usually takes place over distance, whereas transfer of tacit knowledge generally requires on-site demonstration, and hence face-to-face communication between headquarters and subsidiaries is often crucial (Bresman, et al., 1999).

Thus, the available literature clearly shows that the geographical distance could represent a barrier to an effective knowledge transfer. Moreover, several studies have also demonstrated that geographical distance could be a measure of cultural distance (Shenkar, 2001; Siegel et al., 2013; Kogut and Singh, 1988; Håkanson and Ambos, 2010), resulting in another barrier to an efficient knowledge transfer (Thomas, 2006; Johnson et al., 2006). Indeed, the more a place is geographically distant to another, more their respective cultures differ, resulting in transfer complications (Petruzzelli, 2001; Harzing and Noorderhaven, 2006; Holmstrom et al., 2006; Ambos and Ambos, 2009). However, in instances of cultural disparity, managers' Cultural Intelligence could be a facilitator to overcome these issues, as the next paragraph shows.

\subsection{Cultural Intelligence and Expatriate Managers}

In the early 2000s, the entirely new concept of Cultural Intelligence was defined as a multidimensional construct, encompassing an individual's capability to function and manage 
effectively in settings involving cross-cultural interactions (Earley and Ang, 2003). Subsequently, Peterson (2004) further investigated how cultural values and attitudes of individuals interacted, providing the following definition of Cultural Intelligence: "the ability to engage in a set of behaviours that uses skills (i.e. language or interpersonal skills) and quantities (e.g. tolerance for ambiguity; flexibility) that are tuned appropriately to the culture-based values and attitudes of the people with whom one interacts" (p. 106). Thus, Cultural Intelligence can be more broadly defined as a person's evolutionary capability to adapt to a wide range of cultures (Early and Ang, 2003). Drawing on the need to understand the role of individual differences in influencing cultural adaptation, Earley and Ang (2003) conceptualised Cultural Intelligence as a multifaceted characteristic consisting of the following elements: Cognitive Cultural Intelligence, Metacognitive Cultural Intelligence, Motivational Cultural Intelligence, and Behavioural Cultural Intelligence.

Cognitive Cultural Intelligence refers to the specific knowledge of a group's values, beliefs, and practices. Metacognitive Cultural Intelligence refers to an individual's level of conscious awareness regarding cultural interactions, along with their ability to strategize when experiencing diverse cultures. Motivational Cultural Intelligence refers to the ability to channel energy and attention toward gaining knowledge about cultural differences. Lastly, Behavioural Cultural Intelligence is the ability of an individual to be flexible in modifying behaviours, appropriately using verbal and physical actions, in cross-cultural interactions.

Although Cultural Intelligence is still in its early stages, empirical evidence is growing within the context of teamwork (Adair et al., 2013; Flaherty, 2008), decision-making (Ang et al., 2007), leadership (Groves and Feyerherm, 2011), and expatriates (Kim, Kirkman, and Chen, 2008; Elenkov, and Manev, 2009; Lee and Sukoko, 2010). Thus, Cultural Intelligence is a relevant skill needed by managers to compete in a multicultural environment, and several scholars have demonstrated that Cultural Intelligence has an extensive impact on manger's performance and tasks, especially in a global and international context (Lee and Sukoko, 2010; Groves and Feyerherm, 2011).

Directly related to expatriates, Rose at al., (2010), have shown that Behavioural Cultural Intelligence positively relates to job performance, especially regarding contextual and assignment-specific performance. The authors theorize that this relationship could be attributed to a manager's ability to be flexible in their verbal and non-verbal behaviours, in order to meet the expectations of other people. In short, the individual must have a conscious awareness of cultural interactions to allow for better communication. Although Cultural Intelligence shows that individuals are capable of using their knowledge to actively employ appropriate behaviours in specific cultural contexts, only a few studies have investigated the role of Cultural Intelligence in expatriate performance and behaviour; especially in the knowledge transfer process (Lee and Sukoko, 2010; Wu and Ang, 2011; Boh et al., 2013).

Thus, managers, especially those in higher positions such as senior managers, are responsible for the intermediation between MNCs and subsidiaries in the knowledge transfer process. Consequently, our focus is on the senior expatriate manger (Minbaeva et al., 2003; Barry Hocking et al., 2004; Minbaeva and Michailova, 2004). Accordingly, Lee and Sukoko (2010) studied how Cultural Intelligence and expatriates' experience influenced cultural adjustment, cultural effectiveness, and expatriates' performance. The outcomes revealed that the positive influence of Cultural Intelligence requires mediation by cultural adjustment and cultural effectiveness prior to shaping expatriate performance. Expatriates' previous international work and travel experiences further moderate the effects of Cultural Intelligence on cultural adjustment and cultural effectiveness. Moreover, Wu and Ang (2011) 
tested the relationships between corporate expatriate supporting practices, cross-cultural adjustment, and expatriate performance, employing a sample of 169 expatriate managers in Singapore. Their assessment revealed that expatriate supporting practices are positively connected to both adjustment and performance. Furthermore, while motivational Cultural Intelligence had a positive moderating effect, metacognitive and cognitive Cultural Intelligence negatively moderated the links between expatriate supporting practices and adjustment. Finally, only Boh et al., (2013) examined factors that impact knowledge transfer from the parent corporation to subsidiaries when there are differences in the national culture of the parent corporation and the subsidiary. The study analyses how trust, cultural alignment, and openness to diversity influence the effectiveness of knowledge transfer from the headquarters to the employees in the subsidiary, and the findings revealed that an individual's trust of the headquarters and their openness to diversity are crucial factors influencing local employees' ability to learn and obtain knowledge from foreign headquarters.

Therefore, the role of expatriate Cultural Intelligence seems to be gaining an increasing importance because they are the "link" connecting MNC headquarters to their respective subsidiaries (Minbaeva et al., 2003; Barry Hocking et al., 2004; Minbaeva and Michailova, 2004). However, there is no mention of Cultural Intelligence as a crucial factor in expatriates' competencies in previous studies.

\section{Hypothesis Development}

As highlighted in the previous paragraph, the available literature addressing factors that can have an impact on the success of knowledge transfer is vague in stressing the outcome that a specific factor has (Caligiuri, 2014). When specifically addressing international business, management literature focuses on individual knowledge transfer facilitators and barriers, emphasizing factors such as motivation (Caligiuri, 2014), leadership (Raab et al., 2014), openness (Boh et al., 2013), gender (Peltokorpi and Vaara, 2014), and autonomy (Rabbiosi, 2011). However, despite the increasing interest in the effect of Cultural Intelligence on expatriates, the number of studies assessing the role of Cultural Intelligence in knowledge transfer in MNCs is lacking. However, as several previous studies have suggested, there is a connection between Cultural Intelligence and knowledge transfer (Buckley et al., 2006; Lee and Sukoko, 2010; Boh et al., 2013), especially with regard to the role of the expatriate manger as acting "link" between MNCs and subsidiaries (Minbaeva et al., 2003; Barry Hocking et al., 2004; Minbaeva and Michailova, 2004). Moreover, as these seminal studies suggested, the cultural awareness could be a facilitator of the knowledge transfer process, both conventional and reverse. Consequently, it is possible to state the following hypotheses:

1. HP1a: Expatriate managers' Cultural Intelligence positively affects the Conventional KT process performance.

2. HP1b: Expatriate managers' Cultural Intelligence positively affects the Reverse KT process performance.

Additionally, the transferring of knowledge within MNCs' networks may be influenced by many factors, such as resource profiles, local embeddedness of the subsidiaries, and internal strategic considerations of the MNC headquarters (Birkinshaw and Hood, 1998; Forsgren and Pahlberg, 1992; Young and Tavares, 2004). Numerous studies have also demonstrated that geographical distance, 
(defined as the physical distance between MNCs and subsidiaries (Hansen, and Løvås, 2004)), could be a measure of cultural distance (Shenkar, 2001; Siegel et al., 2013; Kogut and Singh, 1988; Håkanson and Ambos, 2010). Indeed, several scholars highlight that the more a place is geographically distant to another, the more it is reasonable to assume that the culture is different (Petruzzelli, 2001; Harzing and Noorderhaven, 2006; Holmstrom et al., 2006; Ambos and Ambos, 2009).

Consequently, as the evidence suggests, we might assume that the more the culture is different, the more the positive effect of Cultural Intelligence could become fragile and irrelevant. This could negate the positive effect of Cultural Intelligence in boosting Conventional KT and Reverse KT processes. Thus, very distant and unfamiliar cultures increase the difficulty and the cost in the communication between headquarters and subsidiaries, especially in exchanging knowledge (Zaheer et al., 2012; Asmussen and Goerzen, 2013; Baaij and Slangen; 2013). Accordingly, the prior statements bring us to the formulation of the following hypotheses:

1. HP2a: The increase of geographical distance negatively moderates the relationship between Cultural Intelligence and the Conventional KT process.

2. HP2b: The increase of geographical distance negatively moderates the relationship between Cultural Intelligence and the Reverse KT process.

The following figure (Figure 1) represents the proposed model:

- - - Please insert Figure 1 about here - - -

\section{Methodology}

\subsection{Sample and Data Collection Procedure}

To investigate the relationships among knowledge transfer (conventional and reverse), geographical distance, and Cultural Intelligence, expatriate managers working for Croatian subsidiaries of foreign MNCs were surveyed between December 2014 and February 2015 (Vlajčić, 2015). Expatriate managers were chosen as they act as a main connection in the knowledge transfer process between MNCs and subsidiaries, and they are subjected to cultural complexities (Minbaeva et al., 2003; Barry Hocking et al., 2004; Minbaeva and Michailova, 2004). MNCs were selected according a wide defining, i.e. a company which owns and controls activities in at least two countries (Caves, 1996), and identified using the Orbis database.

All active expatriate managers in Croaita (841) were contacted firstly by phone and, upon agreement to participate in the study, a questionnaire was sent via email. The total of 108 responses were collected, and 103 were fully completed and able to be used. The sample size and response rate is consistent with previous studies done in the same field (Carbonell \& Rodriguez, 2006; Yang et al, 2008; Chevallier et al, 2016).

\subsection{Measurement of Variables}


To test the proposed hypotheses, this study used three categorical variables and one continuous variable.

Independent Variable: The Cultural Intelligence of senior expatriate managers was used as a categorical independent variable. The Cultural Intelligence variable is focused on four dimensions: metacognitive, cognitive, motivational, and behavioural. The Cultural Intelligence Scale (CQS, Ang et al., 2007) was adopted to measure Cultural Intelligence. Items on the scale are self-reported and based on a seven-item Likert scale, ranging from "strongly disagree" to "strongly agree".

Dependent Variables: Conventional KT and Reverse KT are the categorical dependent variables. They are conceptually very similar; however, they use different transfer logic (a teaching vs. a persuading process). According to Yang et al (2008), this allows the same measurement instrument to be used for both variables. To measure Conventional KT and Reverse KT, a seven-item Likert scale ranging from "not at all" to "a very great extent" was used, and a measurement system for these variables was adopted from Yang et al. (2008) and Najafi-Tavani et al. (2012). For measuring Conventional KT and Reverse KT, six-items were used: managerial capabilities, brand names, sales networks and technical innovation capabilities, financial resources for research and development (R\&D), and know-how in manufacturing.

Moderating Variable: This research used Harzing and Noorderhaven's (2006) methodology for the calculation of moderating continuous variable's geographical distance, measuring distance between headquarters capital cities and subsidiaries capital cities. We operationalized geographical distance using the European Commission's distance calculator (Marcon and Puech, 2003).

Control Variables: The sample was controlled by age, dividing senior expatriate managers in two groups: younger than 45 years old and older than 45 years old, as well as gender. According to Ang et al (2007) and Templer et al, (2006), age and gender play an important role in determining the Cultural Intelligence and cross-cultural adjusting of expatriate managers.

\subsection{Estimation Procedure}

The estimated model is the combination of two sub-models. The first sub-model tests the relationship between Cultural Intelligence, (the independent variable), and conventional knowledge transfer process, (the dependent variable). The second sub-model tests the relationship between Cultural Intelligence, (the independent variable), and reverse knowledge transfer (the dependent variable). The model also contains one moderating variable - geographical distance, the effect of which (inducing or mitigating the impact) on two basic relationships that we are testing will be checked.

The PLS (Pratono, 2016; Eikebrokk et al., 2011) technique for testing the models was preformed using the software package SmartPLS v. 3.2.6. (Ringle, Wende, and Will, 2017). When testing a researched model, in the context of PLS-SEM, a two-stage approach was used (Hair et al., 2017). The PLS multivariate technique was chosen as it allows testing of multiple dependent and independent latent constructs (Mathwick et al, 2008) which, in our case, is more than necessary as two dependent variables must be evaluated at the same time. Additionally, it calculates the relationship between all variables at the same time, and doesn't require multivariate normality (Zhou et al, 2012). The research model was framed in a way that, in the first stage, the latent variable scores (LVs) of each Cultural Intelligence dimension were obtained. This way the number of relationships in the model was reduced, making the model more parsimonious and resistant to collinearity problems (Hair et al., 2016). The second stage consisted of loading latent variable scores (LVs) on Cultural Intelligence 
constructs and, during further analysis, Cultural Intelligence was treated as one construct. Analysis of the measurement model will provide this research with an estimation of how well data fit the proposed theory (Afthanorhan, 2013). The analysis of the structural model will result in path coefficients of statistical significance (using Boothstraping procedure; 5000 sub-samples; HernándezPerlines et al., 2016). The impact of geographical distance was captured using an interactionmoderation effect (Torres and Sidorova, 2015) and, to control age and gender, PLS-MGA was used.

\section{Results}

In this section, the descriptive statistics of the respondent's demographics is presented first, analysis of the measurement model follows, after which the analysis of the structural model is demonstrated, showing the significance of the findings.

The survey respondents were primarily males (79.1\%), indicating an unequal gender distribution of senior management positions in foreign subsidiaries active in the Republic of Croatia. Most senior expatriates in Croatia belong in the age group of 35-45 year olds (38.4\%), while other groups (25-35 $(24.3 \%)$ and $45-55(26.3 \%)$ ) are equally represented. Only $8 \%$ of respondents belonged to the group $55+$. Given the importance of their position in the company, the education level indicates that only $2 \%$ of the sample are managers with only a high school diploma, while bachelor degrees, Master's degrees, Doctoral degrees, or other advanced degrees are distributed respectively $20.0 \%, 56.1 \%$, $16.0 \%$, and $3.0 \%$. For a large number of senior expatriate managers in this survey, this was the first expatriate assignment which was longer than 6 months (33.7\%), while the others in the sample were more experienced in working in international environments, having behind them $2(26.3 \%), 3$ $(15.8 \%), 4(6.3 \%), 5$ or more $(17.9 \%)$ previous assignments abroad for longer than 6 months. Regarding the time spent at the subsidiary, the largest proportions of respondents had already been working more than 36 months in their present subsidiary (44.8\%), while only $7.3 \%$ were newcomers (less than 6 months). The rest of the sample was more or less equally distributed: $14.6 \%$ (6 - 12 months), $19.8 \%$ (12 - 24 months), 13.5\% (24 - 36 months). Finally, industry distribution was quite diverse, having only four groups heavily represented: financial and insurance activities (22.30\%), information and communication (9.60\%), manufacturing $(9.60 \%)$, and wholesale/retail trade and repair of motor vehicles and motorcycles $(8.50 \%)$. The rest were equally distributed among numerous other groups.

- - - Please insert Table 1 about here - - -

This model contains three reflective constructs (Cultural Intelligence, Conventional KT, and Reverse KT), and one continuous variable (geographical distance). Satisfactory loading values, according to Hair et al (1998), are the ones above 0.7. Analysis of the measurement model indicates that 28 out of 32 items from this research possess satisfactory loading values. Research detected four items in which the loading value was below critical level, two components of CKT $(0.698 ; 0.536)$, one component of RKT (0.643), and one component of cognitive CQ (0.593). However, because they were not critically low and they had theoretical importance for the construct definition, they were left in the model (Okazaki and Tailor, 2008). As it is one of the most important measures of uni-dimensionality and is a measurement scale of high internal consistency (Kline, 2011; Tsironis and Matthopoulos, 2015), Cronbach's Alpha for all latent variables was measured. The Cronbach's Alpha of all latent 
constructs was above 0.7. Composite reliability, according to Nunnally and Bernstein (1994), has to be above 0.8 . This model indicated that all latent constructs were well above this level, demonstrating an internal consistency within the measurement model. To evaluate for convergence validity, according to Hair et al (2010), the recommended value for average variance extracted (AVE - the level of latent constructs explained variance by indicators) should be above 0.5. This analysis indicated that all latent constructs satisfied this criterion. Finally, the assessment of models' discriminant validity also relies on AVE, indicating that correlations between each pair of the latent constructs must not exceed the square root of each construct AVE (Fornell and Larcker, 1981), which is the full-field in this model. For details on evaluation of internal consistency data reliability, see estimated parameters in Table 2.

- - - Please insert Table 2 about here - - -

To test the hypothesis on interaction-moderation effect of geographical distance, we first tested the direct relation between CulturalI intelligence and Conventional KT)/ Reverse KT). The relation between Cultural Intelligence and Conventional KT was positive and statistically significant $(\beta=$ $.276 ; \mathrm{t}=2.398 ; \mathrm{p}<.05$; see Figure 2). Similarly, the research also demonstrated a positive and statistically significant relationship between Cultural Intelligence and Reverse KT $(\beta=.284$; $\mathrm{t}=$ 2.829 ; p<.05; Fig. 2). When testing the importance of geographical distance on the relationship between Cultural Intelligence and knowledge transfer, moderation-interaction effect was used (Hair et al., 2016). Results indicated that the impact of geographical distance on the relationship between Cultural Intelligence and Conventional KT is expectedly negative, but statistically insignificant $(\beta=$ $-.15 ; \mathrm{t}=1.246 ; \mathrm{p}>.05 ;$ Fig. 2). This effect implies that, for any increase of geographical distance, Cultural Intelligence's impact on Conventional KT will be reduced by 0.15 , setting new impact to 0.126 . However, as already stated, these results are not statistically backed up. The impact of geographical distance on the relationship between Cultural Intelligence and Reverse KT is also negative but is statistically significant $(\beta=-.181 ; \mathrm{t}=2.453$; $\mathrm{p}<.05$; Fig. 2 ). This effect implies that, for the increase of geographical distance for one standard deviation, Cultural Intelligence's impact on Reverse KT will be reduced by 0.18 standard deviations, setting new impact to 0.104 . For details of tested hypotheses, see Figure 2 or Table 3. Additionally, when testing the interaction effect of geographical distance, the sample had 14 missing values, which is more than $5 \%$ of the overall sample. A deletion method was thus used (Hair et al., 2016).

\section{- - - Please insert Figure 2 about here - - - \\ - - - Please insert Table 3 about here - -}

Finally, when testing control variables (age and gender), PLS-MGA was used. Results of the PLSMGA indicate that there is no statistically significant difference between two sub-samples (younger vs older; female vs male). Additionally, analysis of structural models also presents the $\mathrm{R}^{2}$ and $\mathrm{Q}^{2}$ as a measure for model consistency and predictive relevance. These measures indicate low consistency $\left(\mathrm{R}^{2}(\right.$ Conventional KT $)=0.175 ; \mathrm{R}^{2}($ Reverse $\left.\mathrm{KT})=0.189\right)$ as well as low accuracy and predictive 
relevance $\left(\mathrm{Q}^{2}(\right.$ Conventional KT $)=0.055 ; \mathrm{Q}^{2}($ Reverse $\left.\mathrm{KT})=0.073\right)$ (Neter et al., 1990). These results were expected as the model is relatively small and this is quite common in research on organization's behaviours (Eastman, 1994; Pieterse et al., 2010; Baron et al., 2016)

\section{Discussion}

A very important process in business is the ability to successfully transfer knowledge. Successful knowledge transfer increases company performance and provides a company with a competitive advantage over other companies in the same environment (Hsu, 2012; Weaven et al., 2014). This increase in competitive advantage is of special importance in the context of MNCs (Tallman and Phene, 2007; Mudambi and Swift, 2014). In order to improve their competitive advantage, companies must concentrate on knowledge transfer. For this transfer to be successful, each step of this process must be well understood and systematically planned. In the context of MNCs, the process of knowledge transfer is primarily managed by the expatriate managers, sometimes referred to as 'Agents of Knowledge Transfer' (Kusumoto, 2014), as they are responsible for leading subsidiaries in accordance with the global MNC's strategy (Kusumoto, 2014). Knowledge in MNC's units can be location specific, and the usability of that knowledge developed in specific locations largely depends on specific skill sets, i.e. Cultural Intelligence and carriers needed for adjusting this knowledge to new environments where it is being transferred. However, are these skills powerful enough to overcome the environmental dissimilarity? The main objective of this study was to observe the effect that geographical distance, i.e. environment dissimilarity, relied on expatriate managers' skills (Cultural Intelligence) in the knowledge transfer process.

The research used PLS methodology, and the results of empirical analysis indicated that Cultural Intelligence is almost equally strong and, in the same positive-direction, affects Conventional KT as well as Reverse KT. Additionally, the moderating effect of geographical distance demonstrates a negative but statistically insignificant effect on the relationship between Cultural Intelligence and Conventional KT, compared to the negative but statistically significant effect on relationship between Cultural Intelligence and Reverse KT.

The results of testing the relationship between Cultural Intelligence and knowledge transfer were expected (HP1a and HP1b). These findings support the previous research of Kim et al. (2008), as well Rose at al. (2010), on the importance of a manager's Cultural Intelligence for expatriates' assignment effectiveness and job performance. Namely, Cultural Intelligence is one of the competencies senior managers need to possess in order to successfully complete their tasks, whether those tasks are company governance or knowledge transfer. Cultural Intelligence, as a competency, ensures that managers using a knowledge transfer process will be able to recognise and control the specific cultural environment, as well as be motivated to find a way to overcome differences and understand verbal and non-verbal actions in diverse cultures, which is of paramount importance when conveying and implementing knowledge from another environment.

However, this research model implies that the Cultural Intelligence of expatriate managers is not constant, and that the power of these skills might be mitigated with increases in geographical distances. This implication's foundation rests on the fact that increased geographical distance leads to an increase in location specificity knowledge (HP2a and HP2b) - Knowledge is part of the environment in which it is developed (Cantwell and Mudambi, 2005, Cui, et al. 2006; Asmunssen et al., 2013). 
Location specificity of knowledge is a result of geographic and political aspects of that country, such as the legal and commercial infrastructure, government policies, character and cost of factors of production, or condition of transport and communications (Dunning, 1981). Knowledge obtained from local innovation is very tough to transfer to outside locations as they are formed in alternate circumstances (Borini et al., 2012). The fact that knowledge is solely appropriate to one area diminishes the significance of skills and experience that the manager uses for knowledge transfer (Van Vianen et al., 2004). Location specificity might also decrease a manager's motivation to transfer knowledge and the willingness of executives may also be limited. This is the consequence of differences between two locations: the one in which the knowledge is developed, and the one to which that knowledge should be transferred. Differences could have cultural, social, and economic roots. This may require the manager to adapt the observed knowledge (Van Wijk et al., 2008), which ultimately lowers the validity of the knowledge transferred.

The explanation for the different findings on moderation (interaction) effect that geographical distance has on the relationship between Cultural Intelligence and Conventional/Reverse KT could be rooted in the different transfer logic that Conventional KT is a teaching process, whereas headquarters transfer knowledge is dictated, and subsidiaries are thus obliged to accept it (Bezerra et al., 2013)

With this in mind, geographical distance should not pose a problem in the Conventional KT process, as the knowledge being transferred is imposed and the subsidiary is obliged to accept it no matter how location specific this knowledge is or how demanding this process will be for the expatriate manager's competencies and skills. Headquarters recognize this important knowledge for its business processes, thus making geographical distance, location specificity, and its impact on expatriate skills and competencies less important in this knowledge transfer process (Gupta and Govindarajan, 2000; Zaheer et al., 2012).

On the other hand, Reverse KT is a 'persuading' process, wherein a subsidiary tries to persuade headquarters about the importance of the knowledge it offers. However, because of the huge effort the subsidiary has to invest, Reverse KT is a much more fragile procedure. While the subsidiary tries to convince headquarters about the importance of its knowledge, this process relies heavily on the skills and competencies of carriers, in other words, their Cultural Intelligence could present a significant breakthrough in this process (Asmussen and Goerzen, 2013; Baaij and Slangen; 2013). Geographical distances, which have significant cultural differences, may mean that the knowledge for the specific location in which it was developed is too unique. This could then reflect lower competencies (Cultural Intelligence) in the carriers when conveying information in a foreign environment. Compared to the Conventional KT teaching process, the persuading aspect of Reverse KT could lower the effectiveness of carriers acting in foreign environments (lower Cultural Intelligence). This would be due to the lack of ability in recognizing and controlling the specific Cultural Environment, which is highly important when attempting to persuade headquarters on the validity of the conveyed knowledge (Johnson et al., 2006; Håkanson and Ambos, 2010).

\section{Conclusions}

Scarce resources and highly complex and demanding global environments have made knowledge management one of the favourite focuses of strategic management literature. Furthermore, it has also helped to construct knowledge management as a primary focus for managers in companies around 
the world. This notion particularly refers to MNCs who, alongside the complexities of company governance, confront the geographical disparity of their units. MNC units' geographical dispersion leads to many problems, mostly connected with the cost of physical and cultural distance. The focus of this study is on the knowledge transfer process between subsidiaries and headquarters, and the impact that environmental dissimilarity can have. This research has been done with a sample of foreign subsidiaries active in the Republic of Croatia. Results of this analysis indicate that a senior managers' Cultural Intelligence is a significant factor in Conventional and Reverse KT processes. However, even more interesting is the finding that geographical distance proportionally impacts the relationship between Cultural Intelligence and the knowledge transfer process. Results indicate that geographical distance moderates relationships between Cultural Intelligence and Reverse KT, implying that the larger the distance between a headquarters and a subsidiary, the higher the location specificity of knowledge will be; decreasing the impact that Cultural Intelligence has on Reverse KT. However, the same research shows that geographical distance moderately effects the relationship between Cultural Intelligence and Conventional KT, and is not statistically significant. Growth of geographical distance, diminishing similarities between cultures, and corporate knowledge become more location specific. This impacts the value of the skills and experience that managers use for knowledge transfer. Distinct findings between Conventional (regardless of geographical distance) and Reverse KT (where geographical distance is important) could be explained by the different settings of these two processes - the former being a teaching process and the latter being a persuading process. As previously stated, antecedent research demonstrated that geographical distance might evoke the question of cultural dissonance (Petruzzelli, 2001; Holmstrom et al., 2006; Ambos and Ambos, 2009). Thus, the theoretical contribution of this research is evident in the combination of these two associations in relation to the knowledge transfer process in MNCs. In this way, research implies that the competencies of senior expatriate managers are not equal around the network of subsidiaries, but are dependent on geographic and cultural proximity to their native work environment, which ultimately reflects on successful knowledge transfer processes in MNCs. The theoretical contribution of this research lies in discovering a new way that geographical distance affects the knowledge transfer process through Cultural Intelligence.

The knowledge transfer process is a demanding task for managers, and managers have to be equipped with a special set of skills, i.e. Cultural Intelligence, while confronting foreign cultures on their assignment. Improvement of managerial Cultural Intelligence depends on a manager's own motivation to learn about foreign culture; a motivation typically induced by incentives provided by companies for successfully completed assignments. Managers should devote more time in preparing themselves for assignments by carefully studying the culture in which they will operate. They should be aware of every aspect of their international experience as each experience could be useful in subsequent assignments at some point. Additionally, companies might organize corporate training sessions to equip future expatriate managers with knowledge about operations and customs in a desired country, negotiation processes and managerial best practices (e.g., Caputo, 2016; Borbély and Caputo, 2017). This suggestion refers not only to managers in MNCs, but also to all others facing work in alternate cultural surroundings, whether this be inside the borders of their own country or further afield.

This research can also be practically applied to cost structures surrounding knowledge transfer. Given the ambiguity of the knowledge transfer process and, considering a highly locational/geographical 
dispersed network of subsidiaries, every case of knowledge transfer in MNCs is unique, as the MNC has to focus its efforts on trying to control the cost of knowledge transfer. This study enriches the literature with a new specific model for the knowledge transfer process, directly affecting the ways in which MNCs can deal with this process. This research served to highlight to MNCs the challenges that geographical distance might cause on the knowledge transfer process, potentially leading to the undermining of carriers, senior managers, and competencies. Although the sample is composed of senior managers, it is limited by focusing only on the country of Croatia. However, this leaves the door open for future research to test the same hypotheses in different regions in order to confirm or disconfirm the effect of geographical distance in Cultural Intelligence and the knowledge transfer process in alternate regions.

\section{References}

Adair, W. L., Hideg, I., and Spence, J. R. (2013), "The culturally intelligent team: the impact of team cultural intelligence and cultural heterogeneity on team shared values". Journal of CrossCultural Psychology, Vol. 44 No. 6, pp. 941-962.

Afthanorhan, W. M. A. B. W. (2013), "A comparison of partial least square structural equation modeling (PLS-SEM) and covariance based structural equation modeling (CB-SEM) for confirmatory factor analysis”. International Journal of Engineering Science and Innovative Technology, Vol. 2 No. 5, pp. 198-205.

Ambos, T. C., and Ambos, B. (2009), "The impact of distance on knowledge transfer effectiveness in multinational corporations". Journal of International Management, Vol. 15 No. 1, pp. 1-14.

Ambos, T. C., Ambos, B., and Schlegelmilch, B. B. (2006), "Learning from foreign subsidiaries: An empirical investigation of headquarters' benefits from reverse knowledge transfers". International Business Review, Vol. 15 No. 3, pp. 294-312.

Andersson, U., Dasí, À., Mudambi, R., and Pedersen, T. (2016), “Technology, innovation and knowledge: The importance of ideas and international connectivity". Journal of World Business, Vol. 51 No. 1, pp. 153-162.

Ang, S., and Inkpen, A. C. (2008), "Cultural intelligence and offshore outsourcing success: A framework of firm-level intercultural capability”. Decision Sciences, Vol. 39 No. 3, pp. 337358.

Ang, S., Van Dyne, L., Koh, C., Ng, K. Y., Templer, K. J., Tay, C., and Chandrasekar, N. A. (2007), "Cultural intelligence: Its measurement and effects on cultural judgment and decision making, cultural adaptation and task performance". Management and organization review, Vol. 3 No. 3, pp. 335-371.

Asmussen, C. G., and Goerzen, A. (2013), "Unpacking Dimensions of Foreignness: Firm-Specific Capabilities and International Dispersion in Regional, Cultural, and Institutional Space”. Global Strategy Journal, Vol. 3 No. 2, pp. 127-149. 
Asmussen, C. G., Foss, N. J., and Pedersen, T. (2013), "Knowledge Transfer and Accommodation Effects in Multinational Corporations Evidence from European Subsidiaries". Journal of Management, Vol. 39 No. 6, pp. 1397-1429.

Baaij, M. G., and Slangen, A. H. (2013), "The role of headquarters-subsidiary geographic distance in strategic decisions by spatially disaggregated headquarters". Journal of International Business Studies, Vol. 44 No. 9, pp. 941-952.

Baron, R. A., Franklin, R. J., and Hmieleski, K. M. (2016), "Why entrepreneurs often experience low, not high, levels of stress: The joint effects of selection and psychological capital". Journal of management, Vol. 42 No. 3, pp. 742-768.

Barry Hocking, J., Brown, M., \& Harzing, A. W. (2004), “A knowledge transfer perspective of strategic assignment purposes and their path-dependent outcomes". The International Journal of Human Resource Management, Vol. 15 No. 3, pp. 565-586.

Bezerra, M. A., Costa, S., Borini, F. M., and Oliveira Jr, M. M. (2013), "Reverse knowledge transfer: A comparison between subsidiaries of emerging markets and subsidiaries of developed markets". Iberoamerican Journal Of Strategic Management, Vol. 12 No. 4, pp. 67-90.

Birkinshaw, J., and Hood, N. (1998), "Multinational subsidiary evolution: Capability and charter change in foreign-owned subsidiary companies". Academy of management review, Vol. 23 No. 4, pp. 773-795.

Boh, W. F., Nguyen, T. T., and Xu, Y. (2013). "Knowledge transfer across dissimilar cultures". Journal of Knowledge Management, Vol. 17 No. 1, pp. 29-46.

Borini, F. M., de Miranda Oliveira, M., Silveira, F. F., and de Oliveira Concer, R. (2012), “The reverse transfer of innovation of foreign subsidiaries of Brazilian multinationals". European Management Journal, Vol. 30 No. 3, pp. 219-231.

Buckley, P. J., Clegg, J., and Tan, H. (2006), "Cultural awareness in knowledge transfer to ChinaThe role of guanxi and mianzi”. Journal of World Business, Vol. 41 No. 3, pp. 275-288.

Caligiuri, P. (2014), "Many moving parts: Factors influencing the effectiveness of HRM practices designed to improve knowledge transfer within MNCs". Journal of International Business Studies, Vol. 45 No. 1, pp. 63-72.

Cantwell, J., and Mudambi, R. (2005), “MNE competence creating subsidiary mandates". Strategic management journal, Vol. 26 No. 12, pp. 1109-1128.

Caputo, A. (2013). A literature review of cognitive biases in negotiation processes. International Journal of Conflict Management, Vol. 24 No. 4, pp. 374-398.

Caputo, A. (2016). Overcoming judgmental biases in negotiations: A scenario-based survey analysis on third party direct intervention. Journal of Business Research, Vol. 69 No. 10, pp. 43044312.

Borbély, A., \& Caputo, A. (2017). Approaching negotiation at the organizational level. Negotiation and Conflict Management Research, Vol. 10 No. 4, pp. 306-323. 
Caputo, A., Marzi, G., \& Pellegrini, M. M. (2016). The internet of things in manufacturing innovation processes: development and application of a conceptual framework. Business Process Management Journal, Vol. 22 No. 2, pp. 383-402.

Caputo, A., Pellegrini, M.M., Dabic, M. and Dana L.P. (2016), "Internationalisation of Firms from Central and Eastern Europe: A systematic literature review”. European Business Review, Vol. 28 No. 6, pp. 630-651.

Carbonell, P., and Rodriguez, A. I. (2006), "Designing teams for speedy product development: The moderating effect of technological complexity”. Journal of Business Research, Vol. 59 No. 2, pp. 225-232.

Caves, R. E. (1996), Multinational Enterprise and Economic Analysis, Second Edition, Cambridge University Press, Cambridge, UK

Chevallier, C., Laarraf, Z., Lacam, J. S., and Salvetat, D. (2016), "Competitive intelligence, knowledge management and coopetition: The case of european high-technology firms". Business Process Management Journal, 22(6), 1192-1211.

Colakoglu, S., and Caligiuri, P. (2008). "Cultural distance, expatriate staffing and subsidiary performance: The case of US subsidiaries of multinational corporations". The international journal of human resource management, Vol. 19 no. 2, pp. 223-239.

Cui, A. S., Griffith, D. A., Cavusgil, S., and Dabic, M. (2006), "The influence of market and cultural environmental factors on technology transfer between foreign MNCs and local subsidiaries: A Croatian illustration”. Journal of World Business, Vol. 41 No. 2, pp. 100-111

Cummings, J. L., and Teng, B. S. (2003), “Transferring R\&D knowledge: the key factors affecting knowledge transfer success". Journal of Engineering and technology management, Vol. 20 No. 1, pp. 39-68.

Duan, Y. Q., Nie, W. Y., and Coakes, E. (2010), "Identifying key factors affecting transnational knowledge transfer". Information and Management, Vol. 47 No. 7-8, pp. 356-363.

Dunning, J. H. (1981), "Explaining the international direct investment position of countries: towards a dynamic or developmental approach". Weltwirtschaftliches Archiv, Vol. 117 No. 1, pp. 3064.

Earley, P. C., and Ang, S. (2003), Cultural intelligence: Individual interactions across cultures. Stanford University Press, Palo Alto, CA

Earley, P. C., and Peterson, R. S. (2004), “The elusive cultural chameleon: Cultural intelligence as a new approach to intercultural training for the global manager". Academy of Management Learning and Education, Vol. 3 No. 1, pp. 100-115.

Eastman, K. K. (1994), "In the eyes of the beholder: An attributional approach to ingratiation and organizational citizenship behavior". Academy of Management Journal, Vol. 37 No. 5, pp. 1379-1391. 
Eikebrokk, T. R., Iden, J., Olsen, D. H., and Opdahl, A. L. (2011), “Understanding the determinants of business process modelling in organisations”. Business Process Management Journal, Vol. 17 No. 4, pp. 639-662.

Flaherty, J. E. (2008), "The effects of cultural intelligence on team member acceptance and integration in multinational teams", in Ang, S. and Van Dyne, L. (Eds.), Handbook of cultural intelligence: Theory, measurement, and applications, M.E. Sharpe, Armonk, NY, pp. 192-205.

Fornell, C., and Larcker, D. F. (1981), "Evaluating structural equation models with unobservable variables and measurement error". Journal of Marketing Research, Vol. 18, No. 1, pp. 39-50.

Forsgren, M., and Pahlberg, C. (1992), "Subsidiary influence and autonomy in international firms”. Scandinavian International Business Review, Vol. 1 No. 3, pp. 41-51.

Forsten-Astikainen, R. (2010), "External knowledge transfer mechanisms in service business acquisition", Doctoral dissertation, Lappeenranta University of Technology, Lappeenranta, Finland

Foss, N. J., and Pedersen, T. (2002), "Transferring knowledge in MNCs: The role of sources of subsidiary knowledge and organizational context". Journal of International Management, Vol. 8 No. 1, pp. 49-67.

Frank, A. G., and Ribeiro, J. L. D. (2014), "Influence Factors and Process Stages of Knowledge Transfer between NPD Teams: a model for guiding practical improvements". International Journal of Quality and Reliability Management, Vol. 31 No. 3, pp. 222-237.

Gelfand, M. J., Imai, L., and Fehr, R. (2008), "Thinking intelligently about cultural intelligence”, in Ang, S. and Van Dyne, L. (Eds.), Handbook of cultural intelligence: Theory, measurement, and applications, M.E. Sharpe, Armonk, NY, pp. 375-388.

Ghemawat, P., and Hout, T. (2008), “Tomorrow's global giants. Not the usual suspects". Harvard Business Review, Vol. 86 No. 11, pp. 80-88.

Ghoshal, S., and Bartlett, C. A. (1988), "Creation, adoption and diffusion of innovations by subsidiaries of multinational corporations". Journal of International Business Studies, Vol. 19 No. 3, pp. 365-388.

Gonzalez-Loureiro, M., Kiessling, T., and Dabic, M. (2015). "Acculturation and overseas assignments: A review and research agenda", International Journal of Intercultural Relations, Vol. 49, pp. 239-250.

Grosse, R. (1996), “International technology transfer in services”. Journal of International Business Studies, Vol. 27 No. 4, pp. 781-800.

Groves, K. S., and Feyerherm, A. E. (2011), "Leader cultural intelligence in context: Testing the moderating effects of team cultural diversity on leader and team performance". Group and Organization Management, Vol. 36 No. 5, pp. 535-566.

Gupta, A. K., and Govindarajan, V. (2000), "Knowledge flows within multinational corporations”. Strategic management journal, Vol. 21, No. 4, pp. 473-496. 
Haas, M. R., and Cummings, J. N. (2015), "Barriers to knowledge seeking within MNC teams: Which differences matter most?”. Journal of International Business Studies, Vol. 46 No. 1, pp. 36-62.

Hair Jr, J. F., Hult, G. T. M., Ringle, C., and Sarstedt, M. (2016), A primer on partial least squares structural equation modeling (PLS-SEM). Sage Publications, Thousand Oaks, CA

Hair, J. F., Black, W. C., Babin, B. J., Anderson, R. E., and Tatham, R. L. (1998), Multivariate data analysis (Vol. 5, No. 3, pp. 207-219). Prentice Hall, Upper Saddle River, NJ:

Hair, J. F., Hult, G. T. M., Ringle, C. M., and Sarstedt, M. (2017), A Primer on Partial Least Squares Structural Equation Modeling. 2nd Edition. Sage, Thousand Oaks, CA

Hair, J. F., Ringle, C. M., and Sarstedt, M. (2011), "PLS-SEM: Indeed a silver bullet". Journal of Marketing theory and Practice, Vol. 19 No. 2, pp. 139-152.

Hair, J., Black, W., Babin, B., and Anderson, R. (2010) Multivariate Data Analysis: A Global Perspective. Pearson Education, Upper Saddle River, NY

Håkanson, L., and Ambos, B. (2010), “The antecedents of psychic distance”. Journal of International Management, Vol. 16 No. 3, pp. 195-210.

Hansen, M. T., and Løvås, B. (2004), "How do multinational companies leverage technological competencies? Moving from single to interdependent explanations". Strategic Management Journal, Vol. 25 No. 8-9, pp. 801-822.

Harzing, A. W., and Noorderhaven, N. (2006), "Geographical distance and the role and management of subsidiaries: The case of subsidiaries down-under". Asia Pacific Journal of Management, Vol. 23 No. 2, pp. 167-185.

Harzing, A. W., and Noorderhaven, N. (2006), "Geographical distance and the role and management of subsidiaries: The case of subsidiaries down-under". Asia Pacific Journal of Management, Vol. 23 No. 2, pp. 167-185.

Henseler, J., and Sarstedt, M. (2013). "Goodness-of-fit indices for partial least squares path modeling". Computational Statistics, Vol. 28, No. 2, pp. 565-580.

Henseler, J., Ringle, C. M., and Sinkovics, R. R. (2009), “The use of partial least squares path modeling in international marketing". Advances in International Marketing, 20, 277-319

Henseler, J., Ringle, C.M., and Sinkovics, R.R. (2009), "The use of partial least squares path modeling in international marketing", in Sinkovics, R.R. and Ghauri, P.N. (eds.) New Challenges to International Marketing (Advances in International Marketing, Vol. 20) Emerald Group Publishing Limited, pp. 277 - 319

Holmstrom, H., Conchúir, E. Ó., Agerfalk, J., and Fitzgerald, B. (2006), "Global software development challenges: A case study on temporal, geographical and socio-cultural distance". ICGSE'06 Conference Proceedings, IEEE, Florianopolis, Brazil, pp. 3-11. DOI: 10.1109/ICGSE.2006.261210

Hsu, Yu-Shan (2012), "Knowledge Transfer Between Expatriates and Host Country Nationals: A Social Capital Perspective". Doctoral dissertations. The University of Wisconsin-Milwaukee, WI. 
Hymer, S. H. (1976). A study of direct foreign investment. MIT Press, Cambridge, MA.

Imai, L., and Gelfand, M. J. (2010), "The Culturally Intelligent Negotiator: The Impact of Cultural Intelligence (CQ) on Negotiation Sequences and Outcomes". Organizational Behavior and Human Decision Processes, Vol. 112 No. 2, pp. 83-98.

Johnson, J. P., Lenartowicz, T., and Apud, S. (2006), "Cross-cultural competence in international business: Toward a definition and a model”. Journal of International Business Studies, Vol. 37 No. 4, pp. 525-543.

Kalling, T. (2003), "Organization-internal transfer of knowledge and the role of motivation: a qualitative case study”. Knowledge and Process Management, Vol. 10 No. 2, pp. 115-126.

Kim, K., Kirkman, B., and Chen, G. (2008). "Cultural intelligence and international assignment effectiveness". In S. Ang and L. Van Dyne (Eds.), Handbook of cultural intelligence: Theory, measurement, and applications. M.R. Sharpe, Armonk, NY. pp. 71-90.

Kline, R. B. (2011), “Principles and Practices of Structural Equation Modeling”, Third Edition. The Guilford Press, NY.

Kogut, B. and Singh,H. (1988), "The Effect of National Culture on the Choice of Entry Mode", Journal of International Business Studies, Vol. 19 No. 3, pp. 411-432.

Kuemmerle, W. (1999), "The drivers of foreign direct investment into research and development: an empirical investigation”. Journal of international business studies, Vol. 30, No. 1, pp. 1-24.

Kusumoto, M. (2014), "The Role of Expatriates in Cross-Subsidiary Collaboration", in VazquezBrust, D.A., Sarkis, J., Cordeiro, J.J. (Eds.) Collaboration for Sustainability and Innovation: A Role For Sustainability Driven by the Global South? Springer Netherlands, pp. 43-62.

Lee, L. Y., and Sukoco, B. M. (2010), "The effects of cultural intelligence on expatriate performance: The moderating effects of international experience". The International Journal of Human Resource Management, Vol. 21 No. 7, pp. 963-981.

Liyanage, C., Elhag, T., Ballal, T., and Li, Q. (2009), "Knowledge communication and translation-a knowledge transfer model”. Journal of Knowledge management, Vol. 13 No. 3, pp. 118-131.

López-Duarte, C., González-Loureiro, M., Vidal-Suárez, M. M., and González-Díaz, B. (2016), "International strategic alliances and national culture: Mapping the field and developing a research agenda". Journal of World Business, Vol. 51 No. 4, pp. 511-524.

Marcon, E., and Puech, F. (2003). "Evaluating the geographic concentration of industries using distance-based methods". Journal of Economic Geography, Vol. 3 No. 4, pp. 409-428.

Marzi, G., Dabić, M., Daim, T., and Garces, E. (2017). "Product and process innovation in manufacturing firms: a 30-year bibliometric analysis”. Scientometrics, Vol. 113 No. 2, pp. 673704.

Mathwick, C., Wiertz, C., and De Ruyter, K. (2008), "Social capital production in a virtual P3 community". Journal of consumer research, Vol. 34 No. 6, pp. 832-849. 
Millar, C. C., and Choi, C. J. (2009), "Reverse knowledge and technology transfer: imbalances caused by cognitive barriers in asymmetric relationships". International Journal of Technology Management, Vol. 48 No. 3, pp. 389-402.

Minbaeva, D., Pedersen, T., Björkman, I., Fey, C. F., and Park, H. J. (2003), "MNC knowledge transfer, subsidiary absorptive capacity, and HRM". Journal of international business studies, Vol. 34 No. 6, pp. 586-599.

Minbaeva, D. B., and Michailova, S. (2004), "Knowledge transfer and expatriation in multinational corporations: The role of disseminative capacity". Employee relations, Vol. 26 No. 6, pp. 663679.

Mudambi, R. (2002), "Knowledge management in multinational firms". Journal of International Management, Vol. 8 No. 1, pp. 1-9.

Mudambi, R., and Swift, T. (2014), "Knowing when to leap: Transitioning between exploitative and explorative R\&D”. Strategic Management Journal, Vol. 35 No. 1, pp. 126-145.

Mudambi, R., Piscitello, L., and Rabbiosi, L. (2014), "Reverse knowledge transfer in MNEs: Subsidiary innovativeness and entry modes”. Long Range Planning, Vol. 47 No. 1, pp. 49-63.

Najafi-Tavani, L. D. Z., Giroud, S. L. D. A., and Sinkovics, R. R. (2012), "Mediating effects in reverse knowledge transfer processes". Management International Review, Vol. 52 No. 3, pp. 461-488.

Najafi-Tavani, Z., Giroud, A., and Andersson, U. (2014). "The interplay of networking activities and internal knowledge actions for subsidiary influence within MNCs. Journal of World Business, Vol. 49 No. 1, pp. 122-131.

Neter, J., Wasserman, W., and Kutner, M. H. (1990), Applied Linear Models, Regression, Analysis of Variance and Experimental Designs. RD Irwin, Boston, USA.

Ng, K. Y., Van Dyne, L., and Ang, S. (2009). "From experience to experiential learning: Cultural intelligence as a learning capability for global leader development”. Academy of Management Learning and Education, Vol. 8 No. 4, pp. 511-526.

Nunnally, J. C., and Bernstein, I. H. (1994), "The assessment of reliability". Psychometric theory, Vol. 3 No. 1, pp. 248-292.

Okazaki, S., and Taylor, C. R. (2008), "What is SMS advertising and why do multinationals adopt it? Answers from an empirical study in European markets". Journal of Business Research, Vol. 61 No. 1, pp. 4-12.

Peltokorpi, V., and Vaara, E. (2014), "Knowledge transfer in multinational corporations: Productive and counterproductive effects of language-sensitive recruitment". Journal of International Business Studies, Vol. 45 No. 5, pp. 600-622.

Peterson, B. (2004), Cultural intelligence: A guide to working with people from other cultures, Intercultural Press, Yarmouth, Maine, USA 
Petruzzelli, A. M. (2011), "The impact of technological relatedness, prior ties, and geographical distance on university-industry collaborations: A joint-patent analysis. Technovation, Vol. 31 No. 7, pp. 309-319.

Pieterse, A. N., Van Knippenberg, D., Schippers, M., and Stam, D. (2010), “Transformational and transactional leadership and innovative behavior: The moderating role of psychological empowerment”. Journal of Organizational Behavior, Vol. 31 No. 4, pp. 609-623.

Piscitello, L. (2004), "Corporate diversification, coherence and economic performance. Industrial and Corporate Change, Vol. 13 No. 5, pp. 757-787.

Pratono, A. H. (2016), "Strategic orientation and information technological turbulence: Contingency perspective in SMEs". Business Process Management Journal, Vol. 22 No. 2, pp. 368-382.

Raab, K. J., Ambos, B., and Tallman, S. (2014), "Strong or invisible hands? - Managerial involvement in the knowledge sharing process of globally dispersed knowledge groups". Journal of World Business, Vol. 49 No. 1, pp. 32-41.

Rabbiosi, L. (2011), "Subsidiary roles and reverse knowledge transfer: An investigation of the effects of coordination mechanisms". Journal of International Management, Vol. 17 No. 2, pp. 97 113.

Riege, A. (2007), "Actions to overcome knowledge transfer barriers in MNCs". Journal of knowledge management, Vol. 11 No. 1, pp. 48-67.

Ringle, C. M., Wende, S., and Will, S. (2017), Smart PLS v. 3.2.6, SmartPLS, Hamburg (available at www.smartpls .de).

Rose, R. C., Ramalu, S. S., Uli, J., and Kumar, N. (2010), "Expatriate performance in international assignments: The role of cultural intelligence as dynamic intercultural competency". International Journal of Business and Management, Vol. 5 No. 8, pp 76-85

Saliola, F., and Zanfei, A. (2009), "Multinational firms, global value chains and the organization of knowledge transfer". Research Policy, Vol. 38 No. 2, pp. 369-381.

Shannon, C.E. and Weaver, W. (1949) The Mathematical Theory of Communication. University of Illinois Press, Urbana, IL

Shenkar, O. (2001), "Cultural distance revisited: Towards a more rigorous conceptualization and measurement of cultural differences”. Journal of international business studies, Vol. 32 No. 3, pp. 519-535.

Siegel, J. I., Licht, A. N., and Schwartz, S. H. (2013), "Egalitarianism, cultural distance, and foreign direct investment: A new approach”. Organization Science, Vol. 24 No. 4, pp. 1174-1194.

Søndergaard, S., Kerr, M., and Clegg, C. (2007), "Sharing knowledge: contextualising sociotechnical thinking and practice”. The Learning Organization, Vol. 14 No. 5, pp. 423-435.

Szulanski, G. (2000), “The process of knowledge transfer: A diachronic analysis of stickiness. Organizational behavior and human decision processes, Vol. 82 No. 1, pp. 9-27.

Tallman, S., and Phene, A. (2007), "Leveraging knowledge across geographic boundaries". Organization Science, Vol. 18 No. 2, pp. 252-260. 
Templer, K. J., Tay, C., and Chandrasekar, N. A. (2006). "Motivational cultural intelligence, realistic job preview, realistic living conditions preview, and cross-cultural adjustment". Group \& Organization Management, Vol. 31 No. 1, pp. 154-173.

Thomas, D. C. (2006). "Domain and development of cultural intelligence: The importance of mindfulness". Group and Organization Management, Vol. 31 No. 1, pp. 78-99.

Thomas, D. C., and Inkson, K. (2004). Cultural intelligence: People skills for global business: Berrett-Koehler, San Francisco, CA

Tihanyi, L., Swaminathan, A., and Soule, S. A. (2012). International subsidiary management and environmental constraints: The case for indigenization. In Tihany, L., Pedersen, T. and Devinney, T. (Eds.) Institutional Theory in International Business and Management. Emerald Group Publishing Limited, pp. 373-397

Tompson, R., Barclay, D. W., and Higgins, C. A. (1995), "The partial least squares approach to causal modeling: Personal computer adoption and uses as an illustration”. Technology Studies: Special Issue on Research Methodology, Vol. 2 No. 2, pp. 284-324.

Torres, R., and Sidorova, A. (2015), "The effect of business process configurations on user motivation”. Business Process Management Journal, Vol. 21 No. 3, pp. 541-563.

Triandis, H. C. (2006), "Cultural intelligence in organizations". Group and Organization Management, Vol. 31 No. 1, pp. 20-26.

Tsironis, L. K., and Matthopoulos, P. P. (2015), "Towards the identification of important strategic priorities of the supply chain network: An empirical investigation". Business Process Management Journal, Vol. 21 No. 6, pp. 1279-1298.

Van Vianen, A. E. M., De Pater, I. E., Kristof-Brown, A. L., and Johnson, E. G. (2004.), "Fitting in: Surface-and deeplevel culttiral differences and expatriates' adjustment". Academy of Management Journal, Vol. 47 No. 5, pp. 697- 709.

Van Wijk, R., Jansen, J. P. and Lyles, M. A. (2008), "Inter- and intra-organizational knowledge transfer: a meta-analytic review and assessment of its antecedents and consequences". Journal of Management Studies, Vol. 45 No. 4, pp. 815-38.

Wang, S., and Noe, R. A. (2010), "Knowledge sharing: A review and directions for future research". Human Resource Management Review, Vol. 20 No. 2, pp. 115-131.

Weaven, S., Grace, D., Dant, R., and R. Brown, J. (2014), "Value creation through knowledge management in franchising: a multi-level conceptual framework". Journal of Services Marketing, Vol. 28 No. (2), pp. 97-104.

Vlajčić, D. (2015), "The Role of Expatriate Managers in Multinational Companies Reverse Knowledge Transfer" (Unpublished doctoral dissertation). University of Zagreb, Faculty of Economics and Business, Zagreb, Croatia.

Wu, P. C., and Ang, S. H. (2011), "The impact of expatriate supporting practices and cultural intelligence on cross-cultural adjustment and performance of expatriates in Singapore". The International Journal of Human Resource Management, Vol. 22 No. 13, pp. 2683-2702. 
Yang, Q., Mudambi, R., and Meyer, K. E. (2008), "Conventional and Reverse Knowledge Flows in Multinational Corporation”. Journal of Management, Vol. 34 No. 5, pp. 882-902.

Young, S., and Tavares, A. T. (2004), "Centralization and autonomy: back to the future”. International Business Review, Vol. 13 No. 2, pp. 215-237.

Zaheer, S., Schomaker, M. S., and Nachum, L. (2012), "Distance without direction: Restoring credibility to a much-loved construct". Journal of International Business Studies, Vol. 43 No. 1, pp. 18-27.

Zhou, Z., Zhang, Q., Su, C., and Zhou, N. (2012). "How do brand communities generate brand relationships? Intermediate mechanisms". Journal of Business Research, Vol. 65 No. 7, pp. 890-895. 
Table 1

Descriptive statistics of the respondent's demographics

\begin{tabular}{|c|c|c|c|c|c|c|c|c|c|}
\hline \multicolumn{2}{|c|}{ Gender: } & \multicolumn{2}{|c|}{ Age: } & \multicolumn{2}{|c|}{ Education level: } & \multicolumn{2}{|c|}{$\begin{array}{l}\text { Number of Expatriate } \\
\text { assignments (6 month): }\end{array}$} & \multicolumn{2}{|c|}{ Time spent at the subsidiary: } \\
\hline Female & $18.6 \%$ & $25-35$ & $24.3 \%$ & High school & $2.0 \%$ & 1 & $33.7 \%$ & Less than 6 months & $7.3 \%$ \\
\hline \multirow[t]{4}{*}{ Male } & $79.1 \%$ & $35-45$ & $38.4 \%$ & College degree & $20.0 \%$ & 2 & $26.3 \%$ & $6-12$ months & $14.6 \%$ \\
\hline & & $45-55$ & $26.3 \%$ & Master`s degree & $56.1 \%$ & 3 & $15.8 \%$ & 12 - 24 months & $19.8 \%$ \\
\hline & & $>55$ & $8.1 \%$ & Doctoral degree $(\mathrm{PhD})$ & $16.0 \%$ & 4 & $6.3 \%$ & $24-36$ months & $13.5 \%$ \\
\hline & & & & Other & $3.0 \%$ & 5 or more & $17.9 \%$ & More than 36 months & $44.8 \%$ \\
\hline
\end{tabular}

Industry of the subsidiary:

\begin{tabular}{|c|c|}
\hline Accommodation and food service activities & $4.30 \%$ \\
\hline Administrative and support service activities & $1.10 \%$ \\
\hline Agriculture, forestry, and fishing & $1.10 \%$ \\
\hline Construction & $1.10 \%$ \\
\hline Education & $1.10 \%$ \\
\hline Financial and insurance activities & $22.30 \%$ \\
\hline Human health and social work activities & $2.10 \%$ \\
\hline Information and communication & $9.60 \%$ \\
\hline Manufacturing & $9.60 \%$ \\
\hline Other & $28.70 \%$ \\
\hline Professional, scientific, and technical activities & $6.40 \%$ \\
\hline Real estate activities & $2.10 \%$ \\
\hline Transportation and storage & $2.10 \%$ \\
\hline Wholesale and retail trade; repair of motor vehicles and motorcycles & $8.50 \%$ \\
\hline
\end{tabular}

\section{Table 2}

Correlation matrix, Construct reliability and validity, Discriminant validity

\begin{tabular}{|c|c|c|c|c|c|c|c|}
\hline & $\begin{array}{c}\text { Cronbach } \\
\text { Alpha }\end{array}$ & rho_A & $\begin{array}{l}\text { Composite } \\
\text { Reliability }\end{array}$ & AVE & CQ & CKT & RKT \\
\hline Cultural Intelligence (CQ) & 0.726 & 0.755 & 0.815 & 0.526 & 0.725 & & \\
\hline Conventional Knowledge Transfer (CKT) & 0.829 & 0.855 & 0.873 & 0.538 & 0.243 & 0.734 & \\
\hline Reverse Knowledge Transfer (RKT) & 0.854 & 0.872 & 0.891 & 0.578 & 0.225 & 0.659 & 0.76 \\
\hline
\end{tabular}

Note: Diagonal elements, in bold, present the square root of the AVE

\section{Table 3}

Statistical significance of model relationships

\begin{tabular}{|c|c|c|c|}
\hline & $\begin{array}{l}\text { Original Sample } \\
\text { (O) }\end{array}$ & $\begin{array}{c}\text { T Statistics } \\
(|\mathrm{O} / \mathrm{STDEV}|)\end{array}$ & P Values \\
\hline CQ -> Conventional Knowledge Transfer & 0.276 & 2.398 & 0.017 \\
\hline CQ -> Reverse Knowledge Transfer & 0.284 & 2.829 & 0.005 \\
\hline Geographical distance -> Conventional Knowledge Transfer & -0.294 & 2.081 & 0.038 \\
\hline Geographical distance -> Reverse Knowledge Transfer & -0.294 & 3.18 & 0.001 \\
\hline Moderating Effect 1 -> Conventional Knowledge Transfer & -0.15 & 1.246 & 0.213 \\
\hline Moderating Effect 2 -> Reverse Knowledge Transfer & -0.181 & 2.453 & 0.014 \\
\hline
\end{tabular}


Figure 1 - Proposed model

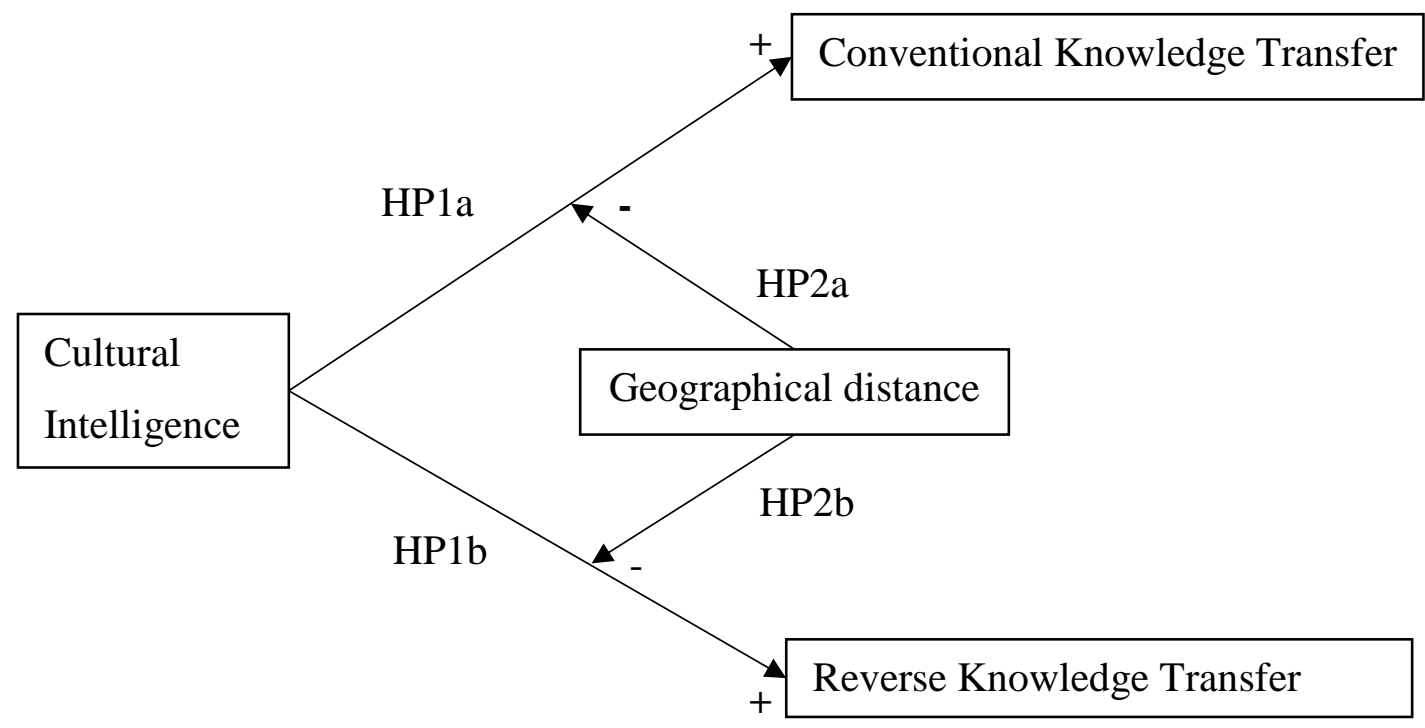

Figure 2 - Analysis of the proposed model

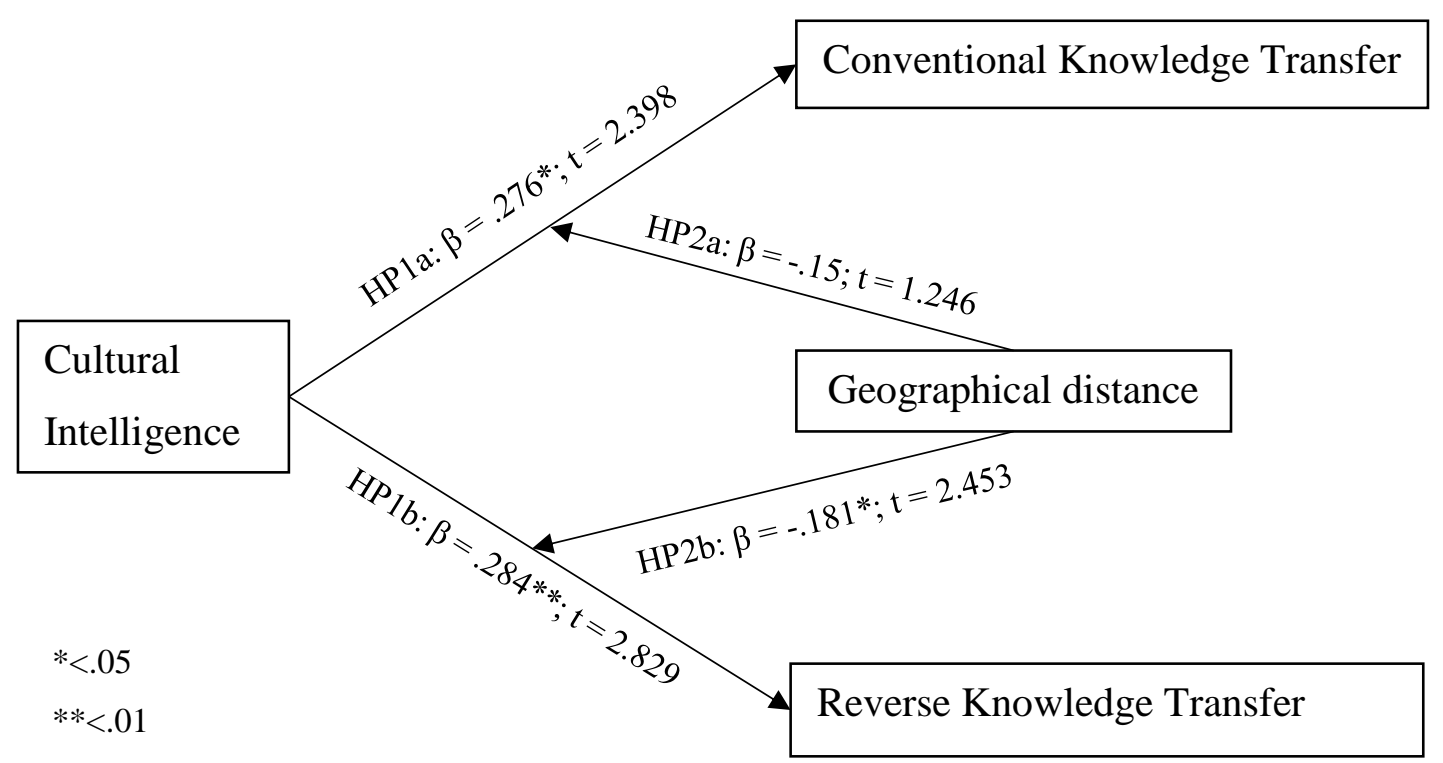

